\title{
Temperature changing process of the Hokkaido (Japan) earthquake on 25 September 2003
}

\author{
W. Ma ${ }^{1}$ W. Ma ${ }^{2}$ H. Zhao ${ }^{2}$, and H. $\mathrm{Li}^{2}$ \\ ${ }^{1}$ Beijing Normal University, Zhuhai Campus, 519085, China \\ ${ }^{2}$ Zhejiang Normal University, Jinghua, 321004, China
}

Received: 23 April 2008 - Revised: 28 July 2008 - Accepted: 28 July 2008 - Published: 5 September 2008

\begin{abstract}
The paper introduced the model of the additive tectonics stress from celestial tide-generating force. The model can be used to explain the relationship between additive tectonics stress and seismic fault sliding. According to the periodic changes of the additive tectonics stress, the temperature is analyzes based on the temperature data of NCEP (National Centers for Environmental Prediction) which are gathered for a period of time before and after the Hokkaido, Japan earthquake (25 September 2003). It is found that the abnormal increasing of the temperature is significantly associated with the seismic deformation, even if the epicenter was covered by the clouds. The effect of the additive tectonics stress on activities of the fault is to trigger it at a time when the stress level has already reached an advanced stage as indicated by the temperature increase. Based on this model, it is possible to forewarn short-impending earthquakes.
\end{abstract}

\section{Introduction}

Before the earthquake, the dynamic changes of the Earth's surface temperature have aroused the concern of many researchers in the studying earthquake prediction (Mogi, 1982; Zhenwen, 1984). In 1988, the former Soviet Union scholar V. I. Gorny (1988), when studied earthquakes in Central Asia, found that large scale abnormal satellite infrared thermal fluctuations before many strong earthquakes in the area. Zongjin (1982) also found that there are abnormal warming before the vast majority of the earthquakes when they did geothermal phenomenon investigation of the nine major earthquakes happened during the years from 1966 to 1976. An abnormally increased infrared temperature before an earthquake can reflect seismotectonic activities (Ouzounov et al., 2004).

Correspondence to: $\mathrm{W} . \mathrm{Ma}$

(weiyuma@163.com)
Since 1972 when the United States land resources satellite - Landsat was launched into space, the remote sensing technology has gained an extremely wide range of applications. Using infrared remote sensing technology, large areas of the Earth's surface temperature distribution can be detected. In 1989, Zuji et al. (1990) began detecting large areas of the Earth's surface temperature distribution and studying its relationship with seismic activity by using infrared remote sensing technology. However, during certain times before the earthquake, for there maybe a lot of the convective clouds in the region, infrared waves can not penetrate clouds. This situation leads to the ground observation satellite can not observe unusual warming phenomenon and thus may omit some forecasts. In addition, the existence of large areas of background warming weather before earthquakes can overshadow the abnormal warming caused by tectonic activity, which will lead to wrong forecast. The NCEP global reanalysis data is used to solve these problems. The NCEP data are based on the temperature of the Earth's ground and supplemented by other available data measured at the same time. So the observing system can be worked as accurately as possible to eliminate the impact of those updating information. The NCEP data is the most comprehensive, global re-analysis of meteorological data for its characteristics of long time scales, broad space scope, and unified global standard and without interference of clouds (Kalnay et al., 1996).

In order to obtain effective information about abnormal warming rate and warming regional image, the program provided by NCEP can be used to make reduction computing between temperature image and its background image for the same region. Although the accuracy of the NCEP temperature data is somewhat coarse, it can better meet the requirement of monitoring such a wide range of infrared abnormal warming of impending earthquakes. It is currently act as a stable and reliable source of information to forecast global tectonic seismic activities.

Published by Copernicus Publications on behalf of the European Geosciences Union. 


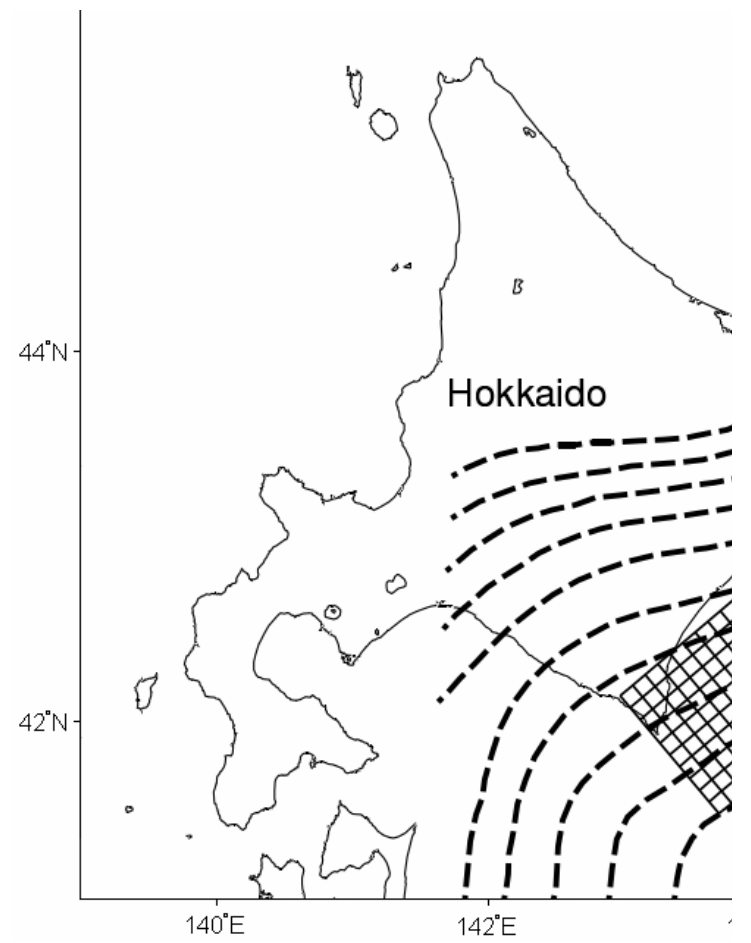

Fig. 1. The epicenter of the 2003 Hokkaido earthquake determined by JMA (solid star). The dashed depth contours in $\mathrm{km}$ represent the upper boundary of the Pacific slab subducting under Hokkaido (Katsumata et al., 2004; Earthquake Research Committee, 2003).

However, how to identify the abnormal temperature changes before earthquakes confronts us with such a question as: in which period the reference background temperature should be chosen.

Seismic movement within the Earth is a mechanical process and the Earth's interior seismic tectonic activity is one of the most key internal factors of earthquake. However, the Earth is not an isolated celestial body and its running is affected by various factors from the cosmic environment, in which the astronomical tide is a major external factor of earthquake (McNutt et al., 1981; Heaton, 1975). In this paper, the model of Additive Tectonics Stress from Celestial Tide-generating Force (ATSCTF for short) is introduced to act as a new method to select the period in which the reference background temperature can be chosen.

In this paper, the large earthquake in Tokachi-oki,(in Hokkaido,Japan) is the study object. The concise information about the earthquake is stated as follows: origin time $=25 / 09 / 2003$, UTC 19:50:06 (UTC: Coordinated Universal Time); depth $=27 \mathrm{~km}$; moment magnitude $(\mathrm{Mw})=8.1$. In the region of Tokachi-oki, Hokkaido, the Pacific plate subducts toward $\mathrm{N} 60^{\circ} \mathrm{W}$ beneath Hokkaido from the Chishima (Kuril) trench at a rate of about $80 \mathrm{~mm} / \mathrm{year}$ (DeMets et al., 1990). This earthquake is the largest event around the Japan islands after the Mw8.2 Hokkaido Toho-oki earthquake in 1994. JMA (2003) located its epicenter above

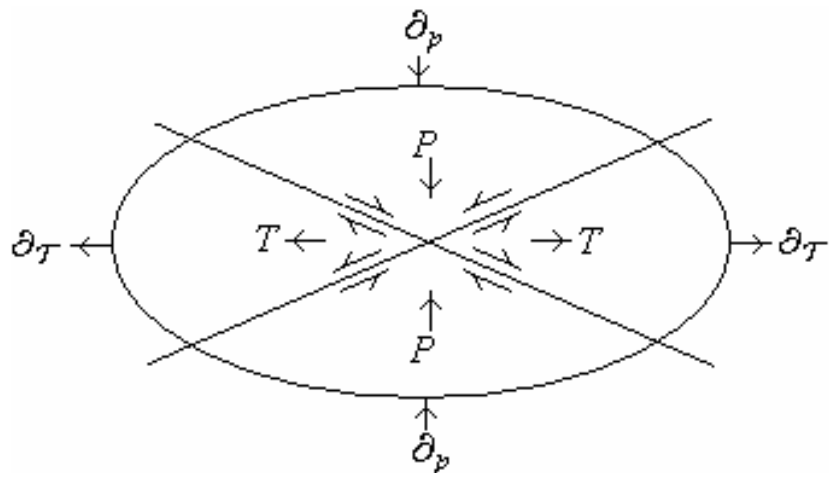

Fig. 2. The additive tectonic stress of celestial tide-generating force on the seismic fault.

the subducting Pacific slab (41_46.78' N, 144_4.71' E; Fig. 1).

The rest of the paper is organized as follows. Section $2 \mathrm{de}-$ scribes the model of ATSCTF in details. In Sect. 3, through using the data from NCEP, the abnormally increasing evolution of the temperature of the large earthquake occurred in Tokachi-oki is described. Section 4 concludes the paper.

\section{The model of ATSCTF on seismic fault}

\subsection{How additive tectonics stress acts on seismic fault}

The gravity from celestial bodies, such as the Sun or the Moon, to the geocentric or any point within the Earth is defined as the celestial tide-generating force. When decomposing the sum celestial tide-generating force of the Sun and the Moon to the main pressure (P-axis) and tension stress $(\mathrm{T}$ axis), the additive tectonic stress $-\partial P$ and $\partial T$ can be worked out as showed in Fig. 2 (Weiyu et al., 2007). According to the process of earthquake, the direction which the additive tectonic stress on seismic fault and structural tectonic activity field varies, so the direction of $\partial P$ and $\partial T$ varies, too. The additive tectonics stress acts on seismic fault can be classified into the following five types by the directions of $\partial P$ 's and $\partial T$ 's changes (as shown in Fig. 2):

(1) Pressurization sliding: the directions of $\partial P$ 's and $\partial T$ 's changes are the same with $P, T$;

(2) Depressurization sliding: the directions of $\partial P$ 's and $\partial T$ 's changes are opposite to $P, T$;

(3) Pressurization and tension reducing sliding: the direction of the $\partial P$ 's change is the same with $P$, but the direction of $\partial T$ 's change is opposite to $T$;

(4) Depressurization and tension increasing sliding: the direction of $\partial P$ 's change is opposite to $P$, but the directions of $\partial T$ 's change are the same with $T$;

(5) No sliding: the directions of $\partial P$ 's and $\partial T$ 's changes are parallel to the central axis.; 

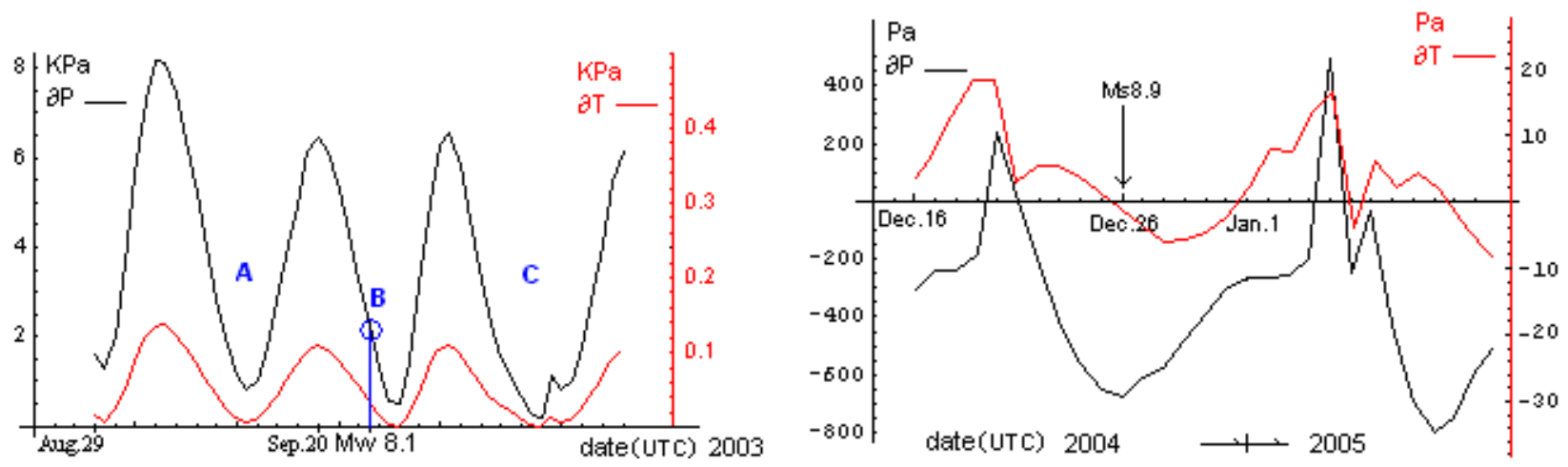

Fig. 3. The change of $\partial P, \partial T$ in ATSCTF model.

Through above classification, there are three ways by which ATSCTF can enhance seismic fault sliding:

(1) The pressure increasing: increases the compressive stress and the shear stress in the fault plane, increases the fault tension until it reaches a critical state and induces an earthquake;

(2) The pressure reducing: not only reduces the positive stress of the fault plane, but also the friction of the fault plane, thereby, triggering the earthquake;

(3) Sometimes the pressure increasing and sometimes the pressure reducing: usually changes the unilateral force and breaks the balance of the fault plane, thereby releasing the energy already stored and triggering the earthquake.

2.2 The using of ATSCTF model on the earthquake in Tokachi-oki, Hokkaido, 2003

Applying of the above model to analyze the additive tectonic stress of Tokachi-oki, Hokkaido from 29 August 2003 to 19 October 2003, a series of values of $\partial P$ and $\partial T$ is worked out. Figure 3 a shows the dynamics of $\partial P$ and $\partial T$ during that period, and there are three cycles. The relationship between the earthquake and its additive tectonic stress can be analyzed through the figure.

The directions of $\partial P$ and $\partial T$ 's change at the occurrence time of the earthquake were opposite to vector of $P, T$. The effect of the ATSCTF on earthquake belonged to "Depressurization sliding" type. This is similar to the earthquake of Indonesia on 26 December 2004 (Fig. 3b) (Weiyu et al., 2006). Both of them occurred on slow slip plate boundaries as showed in cycle "B" in Fig. 3a. According to ATSCTF model, the pressure reduces not only the positive stress of the fault plane, but also the rupture-slide intensity of the fault plane, then makes the fault stress status reach the critical point and advance the fault slide. During the three cycles, the earthquake occurred at the middle cycle when the additive tectonic stress reaches a relatively lower value but not, as usually expected, the time of turning point. It implied that

the accelerate action of the additive tectonic stress is successive, and the instantaneous change of the additive tectonic stress didn't spring the earthquake in suddenly but until the tectonic stress reach the critical broken point. In other two same cycles $\mathrm{A}$ and $\mathrm{C}$, there are no earthquake occurred, for there are no temperature changes. It also indicated that the ATSCTF can't induce the earthquake directly by itself, the decisive is seismotectonic activity. The progress of the fault activity can be reflected through the changes of temperature.

\section{The evolution of abnormal increasing of the tempera- ture based on NCEP data}

An infrared temperature abnormal increasing before an earthquake reflects seismotectonic activity (Ouzounov et al., 2004). However, when there are lots of clouds over the epicenter region, the temperature changing will not be recorded correctly. As showed in Fig. 4, different colors denote different temperatures. The white region means it was covered by clouds and the ground temperature can not directly be measured. So it is impossible to get the accurate temperature changing under clouds.

Tramutoli et al. (2005) have calculated the temperature by RETIRA index $\left(\partial\left(r, t^{\prime}\right)\right)$, but their statistics-based method need a large number of statistic data and usually cannot bring out the small temperature changes before earthquakes. Here we use an analytical method subtracting the normal background image from a series of temperature images according to the ATSCTF cycles (where the ATSCTF values goes through maximum, a minimum and a maximum again) based on NCEP data. This procedure is done in order to reduce disturbances from other factors and extract the abnormal temperature increase caused by activities in the Earth's crust. Taking the temperature values of $1000 \mathrm{hPa}(\mathrm{hPa}$ : hundred $\mathrm{Pa}$ ) on the sea surface on 20 September 2003 (UTC 18:00) as normal background (the ATSCTF value being at maximum), we subtract it from day by day the temperature values of 2328 September for the same time, the same area and altitude. Thus we obtain a series of images shows the variations temperature (Fig. 5). 

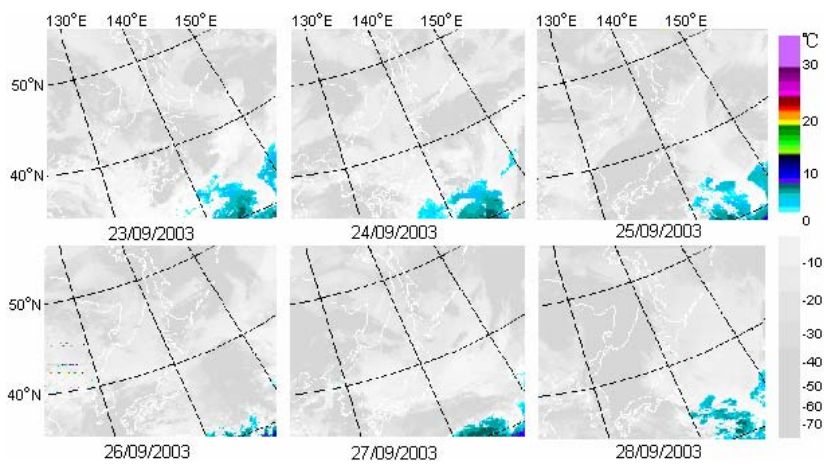

Fig. 4. Brightness temperature images of FY-2 meteorological satellite of China (at 18:51 UTC) Note: The color bar in the right indicates the different temperature with Celsius scale.

It is very clearly showed in Fig. 5 that there is no abnormal temperature increase yet on 23 September 2003; On the 24th, an abnormal temperature increasing up to $5^{\circ} \mathrm{C}$ appears in the south and the north of the future epicenter; On the 25th, an even higher temperature increase is recorded, reaching $7^{\circ} \mathrm{C}$ and the lateral extent of the abnormally hot area increases significantly and the main earth shock occurred; On the 26th, the earthquake was over, the temperature decreased and the area of the anomaly became smaller; On the $27 \mathrm{th}$, the temperature anomaly has further shrunk; On the 28th, the temperature returned to its normal value. In addition, there are no comparable abnormal temperature changes in the other two cycles.

The observed temperature changing went through as such successive evolution: normal temperature $\rightarrow$ original temperature rising (on 24th) $\rightarrow$ reaching peak (main earth shock on 25th 19 o'clock) $\rightarrow$ attenuation (after-shock on 26th and 27 th) $\rightarrow$ return to its normal value (on 28th).

\section{Conclusions}

(1) The evolution of additive tectonics stress' change implies that the tectonic stress build-up was correlated to the celestial tide-generating force. It did not suddenly cause the earthquake or induce it, but acted through a successive accelerating evolution.

(2) The time-spatial dynamic evolution images of NCEP temperature, which were extracted according to the cycle of the ATSCTF values displays the successive evolution: initial temperature increase $\rightarrow$ enhanced temperature increase $\rightarrow$ intensification of the temperature increase $\rightarrow$ peak of the temperature increase $\rightarrow$ attenuation $\rightarrow$ return to baseline. This evolution of abnormal temperature changing can clearly indicates the fault activities under tectonics stress: Tectonic movement extrusion $\rightarrow$ Rock micro-breakage $\rightarrow$ Energy accumula-
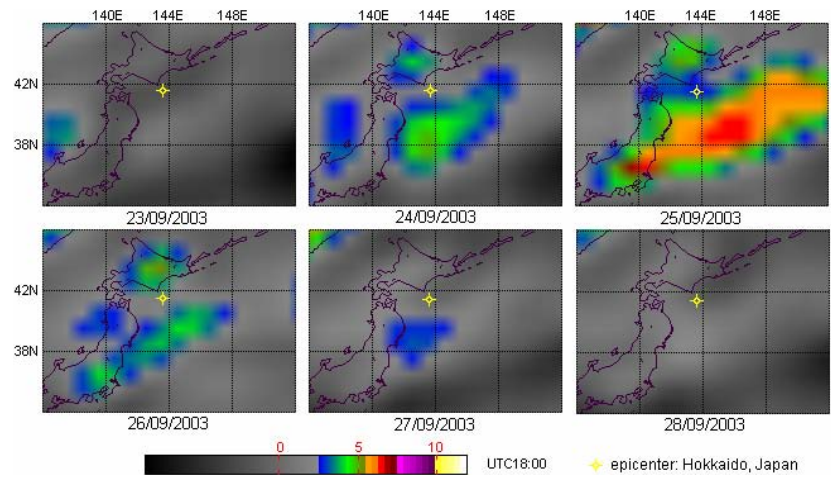

Fig. 5. Spatial-time evolution of abnormal temperature increase of NCEP images Note: the bar on the bottom is the temperature value with Celsius scale.

tion $\rightarrow$ Rock breaking enhancement $\rightarrow$ Energy release $\rightarrow$ Shaking $\rightarrow$ Tranquil.

(3) In the other two cycles of A, C in the ATSCTF, there are no such temperature changes as B cycle. That is to say, the tectonic stress intensity had not reached the critical state to shock, so there is no earthquake occurred. It implies that the celestial tide-generating force could induce the earthquake to occur when the tectonics stress on the active fault is in critical status.

Reviewed by: F. Freund and S. Mukherjee

Edited by: M. Contadakis

\section{References}

An, Z. and Zhu, C.: Study of geothermal variations in relation to large earthquakes (1) - The distribution of thermal stresses in the neighborhood of the sharp end of an elliptical-shaped crack in an infinite elastic medium, Acta Seismologica Sinica, 6(2), 211222, 1984.

An, Z. and Zhu, C.: Study of geothermal variations in relation to large earthquakes (2) - The effect of temperature gradient on fracture propagation direction for strike-slip fault, Acta Seismologica Sinica, 6(4), 382-392, 1984.

DeMets, C., Gordon, R., Argus, D., and Stein, S.: Current plate motion, Geophys. J. Int., 101, 425-478, 1990.

Earthquake Research Committee, Long-term evaluation of earthquakes along the Kuril trench, http://www.jishin.go.jp/main/ chousa/03_mar_chishima/index.html, Headquarters for Earthquake Research Promotion, Tokyo, 2003.

Gorny, V. I., Salman, A. G., Tronin, A. A., and Shilin, B. B.: The Earth outgoing IR radiation as an indicator of seismic activity, Proceeding of the Academy of Sciences of the USSR, 1988, 30(1): 67-69.

Heaton, T. H.: Tidal triggering of earthquakes, Geophys. J. R. Astr. Soc., 43(2), 307-326, 1975.

JMA: Some reports for the 2003 Tokachi-oki earthquake, http: //www.seisvol.kishou.go.jp/eq/2003_09_26_tokachi/index.html, 2003. 
Kalnay, E., Kanamitsu, M., Kistler, R., Collins, W., Deaven, D., Gandin, L., Iredell, M., Saha, S., White, G., Woollen, J., Zhu, Y., Leetmaa, A., Reynolds, R., Chelliah, M., Ebisuzaki, W., Higgins, W., Janowiak, J., Mo, K. C., Ropelewski, C., Wang, J., Jenne, R., and Joseph, D.: The NCEP/NCAR 40-Year Reanalysis Project, Bull. Am. Meteorol. Soc., 77(3), 437-471, 1996.

Katsumata, K., Wada, N., and Kasahara, M.: Newly imaged shape of the deep seismic zone within the subducting Pacific plate beneath the Hokkaido corner, Japan-Kurile arc-arc junction, J. Geophys. Res., 108(B12), 2565, 2003.

Ma, W., Xu, X., Xu, B., and Zhang, X.: Temperature abnormal increase and Astro-tidal-triggering in the tsunami earthquake in Indonesia magnitude 9.0. Earthquake Prediction, [M]: Koninklijke Brill NV, Leiden, The Netherlands, 61-68, 2006.

Ma, Z., Fu, Z., and Zhang, Z.: The nine biggest earthquakes in China 1966-1976, Seismics Press, Beijing, China, 1982.

McNutt, S. R., Beavan, R. J.: Volcanic earthquakes at Pavlof Volcano correlated with the solid earth tide, Nature, 294, 615-618, 1981.
Mogi, K.: Fundamental studies on earthquake prediction, Pres. at ISCSEP, Beijing, China, 16-29, September 1982.

Ouzounov, D., Freund, D.: Mid-infrared emission prior to strong earthquakes analyzed by remote sensing data, Adv. Space Res., 33(3), 268-273, 2004.

Qiang, Z., Xu, X., and Dian, C.: Satellite thermal-infrared abnormal-warning signs of an earthquake, Chinese Sci. Bull., 17, 1324-1327, 1990.

Tramutoli, V., Cuomo, V., Filizzola, C., Pergola, N., and Pietrapertosa, C.: Assessing the potential of thermal infrared satellite surveys for monitoring seismically active areas: The case of Kocaeli (Izmit) earthquake, 17 August 1999, Rem. Sens. Environ., 96, 409-426, 2005.

Ma, W., Zhang, X., and Dai, X.: A preliminary study on the use of NCEP temperature images and addictive tectonic stress from astro-tidal triggering to forecast short-impending earthquakes, Earthquake research in China, 21(1), 85-93, 2007. 